\title{
Trust, but verify
}

\author{
Christoph Haller, MD
}

\footnotetext{
From the Division of Cardiovascular Surgery, Hospital for Sick Children and University of Toronto, Toronto, Ontario, Canada.

Disclosures: Author has nothing to disclose with regard to commercial support.

Received for publication Aug 4, 2016; accepted for publication Aug 6, 2016; available ahead of print Aug 31, 2016.

Address for reprints: Christoph Haller, MD, 555 University Ave, M5G 1X8 Toronto, Ontario, Canada (E-mail: christoph.haller@sickkids.ca).

J Thorac Cardiovasc Surg 2016;152:e127-8

$0022-5223 / \$ 36.00$

Copyright (c) 2016 by The American Association for Thoracic Surgery

http://dx.doi.org/10.1016/j.jtcvs.2016.08.004
}

During the development of the cardiac outflow tracts, the separation into two distinct arterial trunks is a complex process. Fusion of the truncal protrusion with the distal end of the outflow cushions completes this separation. ${ }^{1}$ Failure to close this embryonic aortopulmonary foramen leads to the rare congenital defect of an aortopulmonary window (APW). Although the underlying mechanisms of the development of the coronary plexus giving rise to the coronary arteries are not interrelated with those seen in truncal separation, coexistence of APW with coronary artery anomalies has been described in as many as $10 \%$ of cases. $^{2}$

In this issue of the Journal, Alhadlaq and colleagues ${ }^{3}$ present a rare case of a patient with APW and pulmonary origin of the left coronary artery. Echocardiography identified the communication between aorta and pulmonary artery as well as normal coronary anatomy. Severe depression of left ventricular function was noted after initial repair of the APW, and inadequate flow in the left coronary artery was detected by transesophageal echocardiography. The pulmonary origin of the left coronary artery was confirmed by surgical inspection of the left coronary ostium, and a baffle was used to reroute the coronary artery and close the window.

Although the case and its surgical repair do not present an entirely new clinical scenario, several important concepts of the management of APW can be highlighted. Despite the excellence of echocardiography as a noninvasive preoperative imaging technique, coronary anomalies remain challenging to detect. In particular, the physiologic characteristics of APW, with high pressure in the pulmonary artery and diastolic runoff into the pulmonary vasculature, limit the echocardiographic assessment to a direct visualization of the aberrant coronary ostium. Indirect signs seen in isolated pulmonary origin of the left coronary, such as an enlarged right coronary artery, septal collaterals, retrograde blood flow in the proximal left coronary artery, reduced ventricular function, or mitral valve regurgitation, are usually not encountered. The

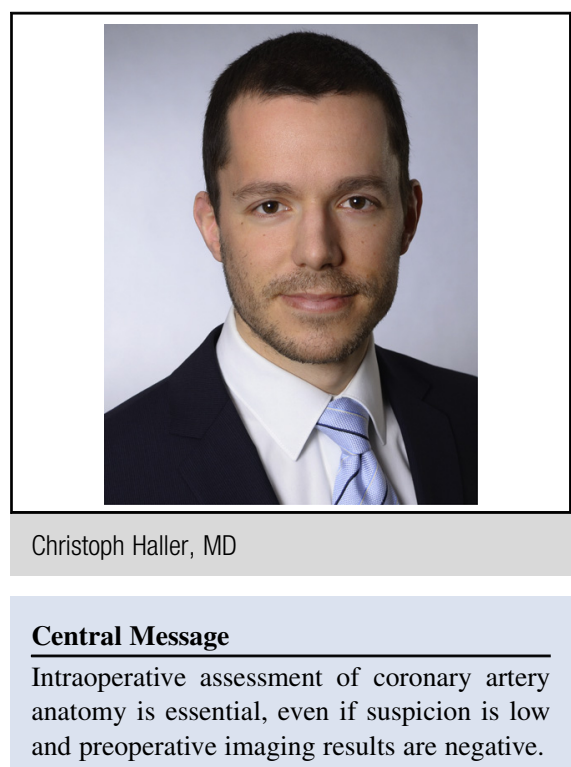

See Article page e123.

anomaly thus may be missed by echocardiography, and any inconclusive imaging should raise the suspicion of a coronary anomaly until demonstrated otherwise. In patients with ambiguous results, transesophageal echocardiography, magnetic resonance imaging, computed tomography, or even diagnostic angiography may be considered. ${ }^{4}$ Although the coronary anomaly can be identified intraoperatively, the upcoming use of transcatheter devices to close the APW makes a thorough assessment of the coronary anomaly even more important, because coexistence changes the therapeutic strategy. Irrespective of the preoperative workup, the ostia of the coronary arteries have to be identified intraoperatively to confirm or refute the initial diagnosis. Unexplained reduced ventricular function, although uncommonly associated with APW preoperatively, should also raise concerns of impaired coronary blood flow, either because the repair itself compromises the coronary artery or because an unrecognized congenital anomaly exists.

Preoperative diagnostic imaging of patients has achieved outstanding reliability. Nevertheless, the case presented by Alhadlaq and colleagues ${ }^{3}$ demonstrates that preoperative imaging and intraoperative assessment are not redundant but rather complement each other. Sometimes, the surgeon's vigilance can make all the difference between a grim and an excellent outcome. 


\section{References}

1. Anderson RH, Chaudhry B, Mohun TJ, Bamforth SD, Hoyland D, Phillips HM, et al. Normal and abnormal development of the intrapericardial arterial trunks in humans and mice. Cardiovasc Res. 2012;95:108-15.

2. Soares AM, Atik E, Cortêz TM, Albuquerque AM, Castro CP, Barbero-Marcial M, et al. Aortopulmonary window. Clinical and surgical assessment of 18 cases. Arq Bras Cardiol. 1999;73:59-74.
3. Alhadlaq A, Dhillon S, Hancock Friesen CL, Hussain A. A hidden culprit for ventricular dysfunction in aortopulmonary window repair: anomalous origin of left coronary artery. J Thorac Cardiovasc Surg. 2016;152:e123-6.

4. Cohen MS, Herlong RJ, Silverman NH. Echocardiographic imaging of anomalous origin of the coronary arteries. Cardiol Young. 2010;20(Suppl 3):26-34. 